\title{
Public Interest in Sports Medicine and Surgery (Anterior Cruciate Ligament, Meniscus, Rotator Cuff) Topics Declined Following the COVID-19 Outbreak
}

\author{
Ajith K. Subhash, B.S., David R. Maldonado, M.D., Trent M. Kajikawa, M.Ed., \\ Sarah L. Chen, B.A., Alexandra Stavrakis, M.D., and Christos Photopoulos, M.D.
}

\begin{abstract}
Purpose: To quantify the coronavirus disease 2019 (COVID-19) pandemic's impact on public interest in sports medicine and surgery topics. Methods: The Google Trends analysis tool (Google Search Volume Indices [GSVI]) was used to collect search information regarding orthopaedic sports medicine terms ("ACL," "meniscus," "rotator cuff") and sports surgery terms ("ACL surgery," "meniscus surgery," "rotator cuff surgery") from May 2015 to May 2020. A time series analysis was performed for these GSVIs and compared to the timing of the pandemic. Results: Interest in both sports medicine and surgery declined following the COVID-19 outbreak. Following the World Health Organization's statement on COVID-19's pandemic status on March 1 1, 2020, searches for "ACL," "meniscus" and "rotator cuff" declined by 34.78\%, 43.95\%, and $31.37 \%$, and search for "ACL surgery," "meniscus surgery" and "rotator cuff surgery" declined by 42.70\%, 51.88\%, and $53.32 \%$, respectively. Conclusion: The COVID-19 outbreak correlated with a decline in public interest in sports medicine and sports surgery topics, as measured by Google searches. Clinical relevance: Orthopaedic sports medicine and arthroscopy patient and surgical case volumes were negatively affected by various factors after the onset of the pandemic. One factor associated with the volume decrease is a decline in public interest.
\end{abstract}

$\mathbf{T}$ The coronavirus disease 2019 (COVID-19) pandemic has significantly impacted the national health care system and imposed unprecedented burdens on the economy at large. ${ }^{1}$ As the numbers of COVID-19 cases steadily increases, the pandemic's impact on the United States (US) hospital's revenue stream has yet to be fully understood. ${ }^{2}$ A major source of hospital revenue is generated by elective,

From the Department of Orthopaedic Surgery, David Geffen School of Medicine at the University of California Los Angeles, Los Angeles, California, U.S.A. (A.K.S., A.S.); Kerlan-Jobe Orthopaedic Institute, Los Angeles, California, U.S.A. (D.R.M., C.P.); Office of Institutional Research, Univrsity of Southern California, Los Angeles, California, U.S.A. (T.M.K.); Sidney Kimmel Medical College, Philadelphia, Pennsylvania, U.S.A. (S.L.C.).

The authors report no potential conflicts of interest or sources of funding. Full ICMJE author disclosure forms are available for this article online, as supplementary material.

Received September 1, 2020; accepted September 16, 2020.

Address correspondence to Ajith K. Subhash, B.S., Department of Orthopaedic Surgery, David Geffen School of Medicine at the University of California Los Angeles, 885 Tiverton Drive, Los Angeles, CA 90095, U.S.A. E-mail:asubhash@mednet.ucla.edu

(C) 2020 THE AUTHORS. Published by Elsevier Inc. on behalf of the Arthroscopy Association of North America. This is an open access article under the CC BY-NC-ND license (http://creativecommons.org/licenses/by-nc-nd/4.0/). 2666-061X/201506

https://doi.org/10.1016/j.asmr.2020.09.004 arthroscopy and orthopaedic sports medicine procedures, and due to the World Health Organization's announcement of COVID-19's pandemic status on March 11, 2020, many of these elective procedures were postponed, contributing to a decrease in surgical case volumes. ${ }^{3,4}$ As COVID-19 cases continue, a decline in arthroscopy and sports medicine procedures could result in financial strain on hospitals and physicians. Physicians and health care institutions are individually required to balance the benefits and risks to public health associated with these surgeries. ${ }^{5}$

The Google Trends tool has been used to predict COVID-19 trends and incidences and is a surrogate for public interest. ${ }^{6,7}$ The purpose of this study was to quantify the COVID-19 pandemic's impact on public interest in sports medicine and surgery topics. Our hypothesis was that a decline in public interest, as measured by Google searches for sports medicine and sports surgery topics, would correlate with the onset of the global pandemic.

\section{Methods}

The Google Trends (Google, Mountainview, CA, US) tool was used to access Google Search Volume Index (GSVI) information relating to sports orthopaedic procedures. GSVIs are an estimate of search activity 
relative to the highest absolute volume of searches, given the search terms queried, and other temporal and geographical parameters $(1-100=$ low to high popularity). Google Trends, as a tool, has been used to analyze public interest in various specialties in medicine..$^{8-12}$

A total of 6 search terms was selected to reflect frequent sports orthopaedic conditions and surgeries. The first category (sports medicine) included the terms "ACL," "meniscus" and "rotator cuff," while the second category (sports surgery) included the terms "ACL surgery," "meniscus surgery" and "rotator cuff surgery."

Weekly GSVI information for the search terms was extracted for May 2015 to May 2020 across the United States. Subsequently, a time series analysis was performed on these weekly GSVIs from March 2019 to May 2020, as described by Jella et al. ${ }^{13}$ This analysis allows for the detection of nonrandom variation in large datasets. Additionally, the number of confirmed COVID-19 cases was accessed via the Centers for Disease Control and Prevention Data Tracker for the US on May 10, 2020. Population data were extracted from the US Census Bureau for 2019. Unemployment data were accessed in June 2020 from the US Bureau of Labor Statistics. In addition, daily regional GSVIs by state and the District of Columbia were extracted across the US from January 1, 2020-May 10, 2020. Values returned as empty GSVIs during regional data extraction were treated as null values. All search terms were queried in June 2020.

States with the highest number of confirmed COVID19 cases per every 100,000 people were compared against states with the largest unemployment percentage change and the largest percentage decrease in GSVIs for the search terms. States were also stratified by their public health policies in effect on April 7, 2020 (mandatory suspension of nonessential activities versus no mandatory restrictions) in order to assess for correlations between the policies and search interest. ${ }^{14} \mathrm{R}$ version 4.0.0 and RStudio version 1.2 (RStudio, Boston, MA) was used for data visualization and statistical analysis.

Table 1. Google Search Volume Index (GSVI) for the Sports Medicine Terms ACL, Meniscus and Rotator Cuff and percentage Change in GSVI from January 1, 2020-March 15 , 2020 versus March 15, 2020-May 10, 2020, Across the US

\begin{tabular}{lccc}
\hline & \multicolumn{2}{c}{ GSVI Values } & \\
\cline { 2 - 3 } Search Term & Jan 1-Mar 15 & Mar 15-May 10 & \% \\
\hline ACL & 32.2 & 21 & $34.78 \%$ \\
Meniscus & 22.4 & 12.56 & $43.95 \%$ \\
Rotator cuff & 23.8 & 16.33 & $31.37 \%$ \\
\hline ACL, anterior & cruciate & ligament; GSVI, Google & Search Volume \\
Index. & &
\end{tabular}

Table 2. Google Search Volume Index (GSVI) for the Sports Surgery Terms ACL, Meniscus And Rotator Cuff and Percentage Change in GSVI from January 1, 2020-March 15, 2020, versus March 15, 2020-May 10, 2020, across the US

\begin{tabular}{lccc}
\hline & \multicolumn{2}{c}{ GSVI Values } & \multirow{2}{*}{$\begin{array}{c}\text { Decrease } \\
\text { Search Term }\end{array}$} \\
\cline { 2 - 3 } \multicolumn{1}{c}{ Jan 1-Mar 15 } & Mar 15-May 10 & in GSVI \\
\hline ACL surgery & 86.1 & 49.3 & $42.70 \%$ \\
Meniscus surgery & 53.8 & 25.9 & $51.88 \%$ \\
Rotator cuff surgery & 64.5 & 30.1 & $53.32 \%$ \\
\hline
\end{tabular}

ACL, anterior cruciate ligament; GSVI, Google Search Volume Index.

\section{Results}

Relative public interest in sports medicine and sports surgery topics has declined following the World Health Organization's statement regarding the COVID-19 pandemic on March 11, 2020. Search results representing relative public interest in "ACL," "meniscus" and "rotator cuff" are shown in Table 1. In Table 2, search results are shown for "ACL surgery," "meniscus surgery" and "rotator cuff surgery." Relative public interest in "ACL," "meniscus," "rotator cuff," "ACL surgery," "meniscus surgery," and "rotator cuff surgery" declined by $34.78 \%, 43.95 \%, 31.37 \%, 42.70 \%$, $51.88 \%$, and $53.32 \%$, respectively, from January 1 , 2020-March 15, 2020, versus March 15, 2020-May 10, 2020 (Fig 1). In addition, average GSVIs were computed in May for each year from 2015-2019 to account for any seasonal variations (Fig 1). All search terms except for "ACL" experienced a sharp decrease in public interest as GSVIs dropped below the lower control limit (3 standard deviations below the mean GSVI).

States, including the District of Columbia (D.C.), with the greatest decrease in public interest for "ACL," "meniscus" and "rotator cuff" were Montana, Alaska and Vermont, respectively (Table 3). States, including D.C., with the lowest relative public interest in "ACL surgery," "meniscus surgery" and "rotator cuff surgery" were South Dakota and D.C., respectively (Table 4). As of May 10, states with the highest number of confirmed COVID-19 cases per 100,000 people were New York $(1,720.2)$, New Jersey $(1,559.7)$, Massachusetts $(1,128.7)$, Rhode Island $(1,064.2)$, and Connecticut (941.1) (Tables 3 and 4). States with a large percentage of increase in unemployment were Nevada, Hawaii, Michigan, New Hampshire, and Indiana. Analysis reveals no clear correlation between public interest by state, by case volume or by employment. It is of note, however, that D.C. appears in 5 of the 6 search term's greatest percentage of decrease in GSVI lists, while also ranking 6th for confirmed COVID-19 cases per capita.

State response varied widely following the World Health Organization's announcement of COVID-19's 

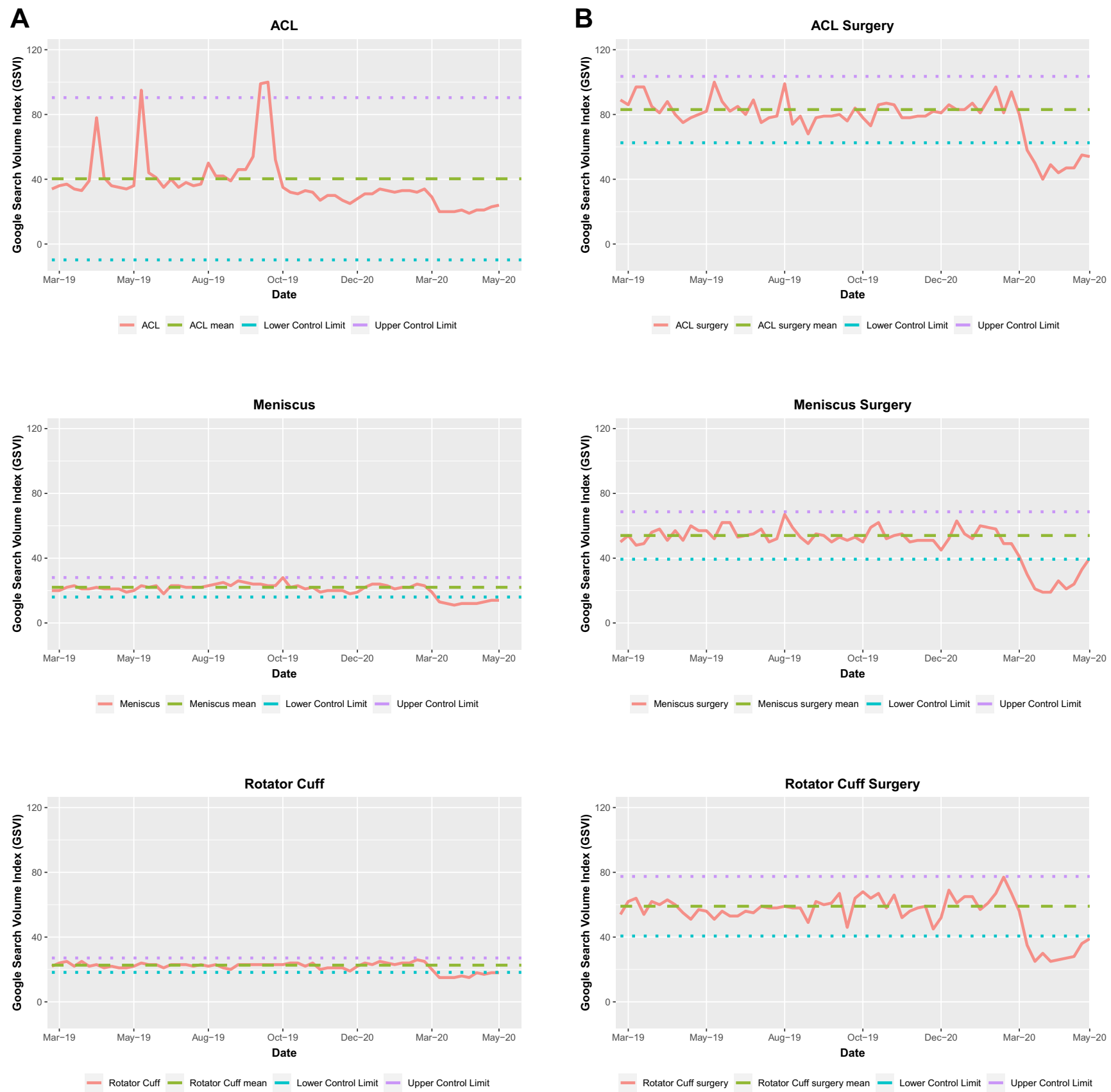

Fig 1. Weekly Google Search Volume Index (GSVI) values plotted from March 2019-May 2020. (A) Represents sports medicine (anterior cruciate ligament [ACL], meniscus, rotator cuff); (B) Represents sports surgery (ACL surgery, meniscus surgery, rotator cuff surgery). *Upper and lower control limits calculated as mean \pm 3 standard deviations. Mean calculated from GSVI from March 2019-2020.

pandemic status. Figure 2 represents each state's official COVID-19 policy on April 7, comparing mandatory suspension of nonessential activities (stay-at-home orders) versus no mandatory restrictions (limited action). Analysis reveals no clear correlation between public interest by states' stay-at-home orders versus states with no mandatory restrictions (limited action) (Tables 5 and 6).

\section{Discussion}

The COVID-19 pandemic has led to a nationwide decrease in public interest in sports medicine and surgery (anterior cruciate ligament $[\mathrm{ACL}]$, meniscus and rotator cuff). Despite the overall decline in public interest, states with the highest numbers of confirmed COVID-19 cases per capita or the highest drops in unemployment did not demonstrate the greatest decrease 
Table 3. Comparison of Top 10 Ranked States (and District of Columbia) for Confirmed COVID-19 Cases Per Capita and for Percentage Increase in Unemployment and by Percentage Decrease in Google Search Volume Indices (GSVI) from January 1 , 2020-March 15, 2020, versus March 15, 2020-May 10, 2020, for Sports Medicine Terms (ACL, Meniscus, Rotator Cuff)

\begin{tabular}{|c|c|c|c|c|c|c|c|c|c|c|}
\hline \multirow{2}{*}{$\begin{array}{l}\text { State } \\
\text { Rank } \\
1\end{array}$} & \multicolumn{2}{|c|}{$\begin{array}{l}\text { Confirmed COVID-19 } \\
\text { Cases per Capita }\end{array}$} & \multicolumn{2}{|c|}{ Unemployment \% Increase } & \multicolumn{2}{|c|}{$\begin{array}{l}\% \text { Decrease in } \\
\text { GSVI for "ACL" }\end{array}$} & \multicolumn{2}{|c|}{$\begin{array}{l}\% \text { Decrease in } \\
\text { GSVI for "Meniscus" }\end{array}$} & \multicolumn{2}{|c|}{$\begin{array}{l}\% \text { Decrease in } \\
\text { GSVI for Rotator Cuff }\end{array}$} \\
\hline & New York & $1,720.20$ & Nevada & $21.30 \%$ & Montana & $-68.76 \%$ & Alaska & $-63.14 \%$ & Vermont & $-57.96 \%$ \\
\hline 2 & New Jersey & $1,559.70$ & Hawaii & $19.90 \%$ & Hawaii & $-53.01 \%$ & New Hampshire & $-62.12 \%$ & South Dakota & $-56.84 \%$ \\
\hline 4 & Rhode Island & $1,064.20$ & New Hampshire & $13.90 \%$ & Indiana & $-43.96 \%$ & Hawaii & $-48.64 \%$ & $\begin{array}{l}\text { District of } \\
\text { Columbia }\end{array}$ & $-51.66 \%$ \\
\hline 5 & Connecticut & 941.1 & Indiana & $13.90 \%$ & Delaware & $-42.53 \%$ & $\begin{array}{l}\text { District of } \\
\text { Columbia }\end{array}$ & $-48.61 \%$ & Kentucky & $-46.65 \%$ \\
\hline 7 & Louisiana & 681.3 & Massachusetts & $12.30 \%$ & Louisiana & $-41.34 \%$ & Maine & $-48.28 \%$ & Delaware & $-44.34 \%$ \\
\hline 8 & Delaware & 674.2 & Rhode Island & $12.30 \%$ & Idaho & $-38.97 \%$ & Idaho & $-47.50 \%$ & Utah & $-42.29 \%$ \\
\hline 9 & Illinois & 613.5 & Illinois & $12.20 \%$ & Vermont & $-38.16 \%$ & Utah & $-46.01 \%$ & Arkansas & $-39.84 \%$ \\
\hline 10 & Maryland & 552.0 & New Jersey & $11.60 \%$ & Connecticut & $-38.02 \%$ & Connecticut & $-45.98 \%$ & Kansas & $-39.10 \%$ \\
\hline
\end{tabular}

${ }^{*}$ Confirmed COVID-19 cases is per 100,000 people. Unemployment change calculated as a percentage difference from March to April 2020. ACL, anterior cruciate ligament; COVID-19, coronavirus disease 2019.

in public interest, nor did states with mandatory stayat-home restrictions versus states with limited action.

Following the World Health Organization's statement of COVID-19's pandemic status on March 11, the U.S. Surgeon General and Centers for Medicare and Medicaid Services recommended limiting nonessential adult elective surgeries. ${ }^{15}$ Local response varied, depending on state officials; however, many highly impacted states, including New York, New Jersey, D.C., and California banned elective procedures and encouraged telehealth in late March. ${ }^{16}$ Many medical practices, particularly those that perform nonessential procedures, saw a significant decrease in patient volume, as offices were forced to transition to telemedicine as well as to comply with social-distancing protocols. This decrease in patient volume was likely due to a combination of factors, including patient unfamiliarity with telemedicine, social distancing concerns during inperson appointments and lack of patients' health insurance. A survey study performed by Moverman et al. found that $61 \%$ of participants were concerned about contracting COVID-19 during surgery. ${ }^{17}$ In addition, patients with orthopaedic issues and concurrent respiratory or cardiovascular illnesses opted to stay at home and postpone their elective procedures. Finally, the majority of Americans receive employer-based health insurance, and the recent stay-at-home orders have forced many nonessential businesses to shut down. As a

Table 4. Comparison of Top 10 Ranked States (and District of Columbia) for Confirmed COVID-19 cases Per Capita, and for Percentage Increase in Unemployment and by Percentage Decrease in Google Search Volume Indices (GSVI) January 1, 2020March 15, 2020, versus March 15, 2020-May 10, 2020, for Sports Surgery Terms (ACL Surgery, Meniscus Surgery, Rotator Cuff Surgery)

\begin{tabular}{|c|c|c|c|c|c|c|c|c|c|c|}
\hline \multirow{2}{*}{$\begin{array}{l}\text { State } \\
\text { Rank } \\
1\end{array}$} & \multicolumn{2}{|c|}{$\begin{array}{l}\text { Confirmed COVID-19 } \\
\text { Cases per Capita }\end{array}$} & \multirow{2}{*}{ Unemployment } & Increase & \multicolumn{2}{|c|}{$\begin{array}{c}\% \text { Decrease in } \\
\text { GSVI for ACL Surgery }\end{array}$} & \multicolumn{2}{|c|}{$\begin{array}{l}\% \text { Decrease in GSVI } \\
\text { for Meniscus Surgery }\end{array}$} & \multicolumn{2}{|c|}{$\begin{array}{c}\% \text { Decrease in GSVI } \\
\text { for Rotator Cuff Surgery" }\end{array}$} \\
\hline & New York & $1,720.20$ & & $21.30 \%$ & South Dakota & $-89.50 \%$ & $\begin{array}{l}\text { District of } \\
\text { Columbia }\end{array}$ & $-100.0 \%$ & $\begin{array}{l}\text { District of } \\
\text { Columbia }\end{array}$ & $-100 \%$ \\
\hline 3 & Massachusetts & $1,128.70$ & Michigan & $18.40 \%$ & $\begin{array}{l}\text { District of } \\
\text { Columbia }\end{array}$ & $-64.24 \%$ & Kentucky & $-84.52 \%$ & Nebraska & $-100 \%$ \\
\hline 4 & Rhode Island & $1,064.20$ & New Hampshire & $13.90 \%$ & Mississippi & $-63.92 \%$ & Ohio & $-64.04 \%$ & Montana & $-84.99 \%$ \\
\hline 7 & Louisiana & 681.3 & Massachusetts & $12.30 \%$ & New Mexico & $-56.96 \%$ & Minnesota & $-60.58 \%$ & Maryland & $-77.07 \%$ \\
\hline 8 & Delaware & 674.2 & Rhode Island & $12.30 \%$ & Idaho & $-56.00 \%$ & Illinois & $-58.54 \%$ & $\begin{array}{l}\text { North } \\
\quad \text { Carolina }\end{array}$ & $-72.81 \%$ \\
\hline 9 & Illinois & 613.5 & Illinois & $12.20 \%$ & $\begin{array}{l}\text { South } \\
\text { Carolina }\end{array}$ & $-54.87 \%$ & Iowa & $-58.36 \%$ & Louisiana & $-69.96 \%$ \\
\hline
\end{tabular}

${ }^{*}$ Confirmed COVID-19 cases per 100,000 people. Unemployment change calculated as a percentage difference from March to April 2020. ACL, anterior cruciate ligament; COVID-19, coronavirus disease 2019. 


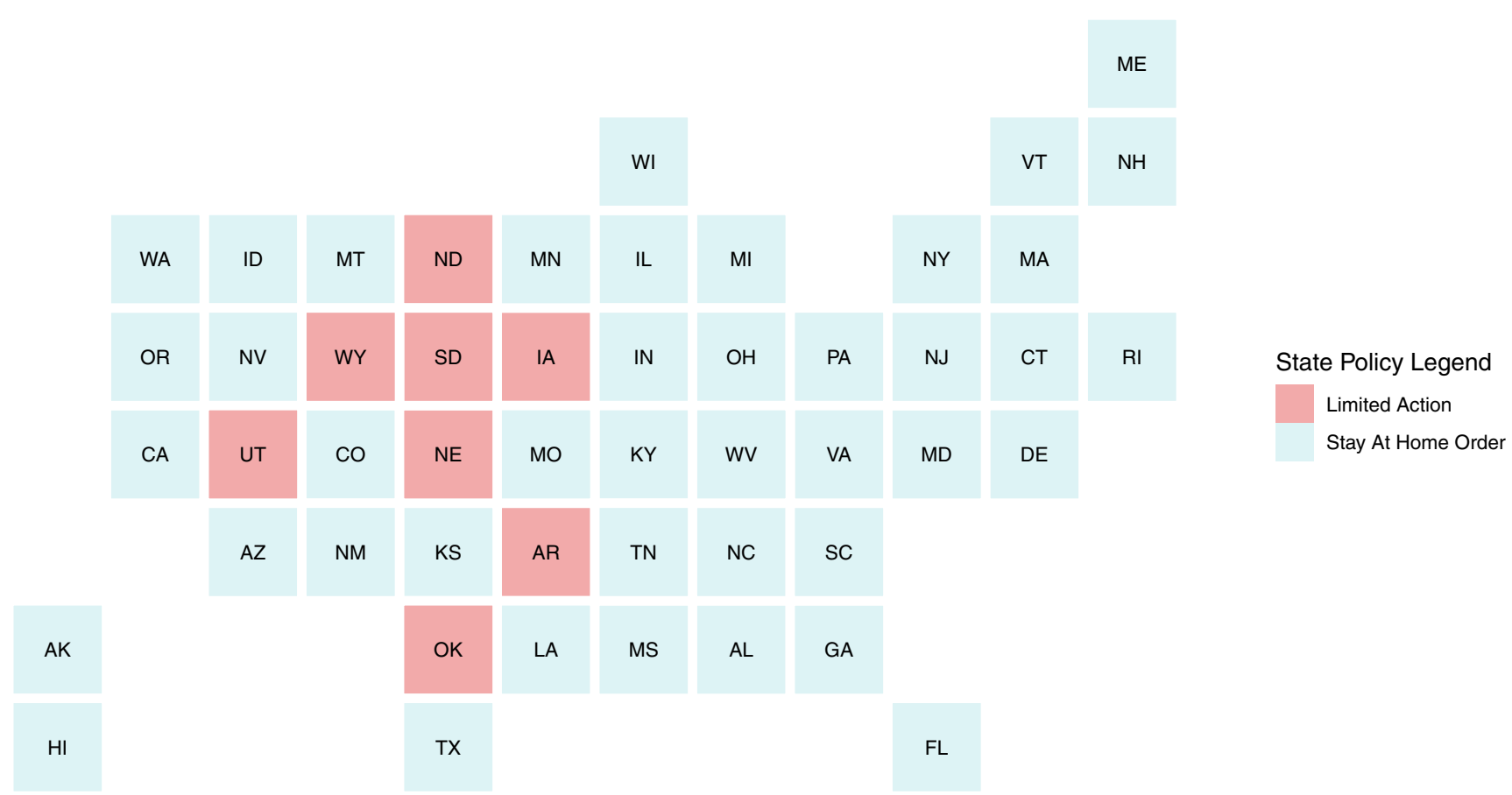

Fig 2. Map of the United States representing individual states' responses to COVID-19 on April 7, 2020. *Stay-at-home order refers to state legislation mandating suspension of nonessential activities. Limited Action refers to social-distancing measures without any mandatory restrictions.

result of the pandemic, at least 17 million Americans have lost employment and, subsequently, their employee-based health insurance. ${ }^{18}$ The decrease in public interest in ACL, meniscus and rotator cuff topics is temporally associated with these changes.

Recent literature has reported on national guidelines and interest in elective orthopaedic procedures during the COVID-19 outbreak. According to Sarac et al., as of March 2020, 30 states recommended discontinuing elective procedures, but only 5 states provided specific orthopaedic guidelines. $^{5}$ Of these states, 4 recommended postponing nontrauma-related orthopaedic procedures, including arthroplasty procedures. ${ }^{5}$ Using GSVI as a proxy, Jella et al. examined public interest in hip- and knee-replacement surgery during the

Table 5. Percentage Decrease in Google Search Volume Index (GSVI) Values Between January 1, 2020-March 15, 2020, versus March 15, 2020-May 10, 2020, for the Terms ACL, Meniscus and Rotator Cuff for all States and Based on State Response

\begin{tabular}{llcc}
\hline & \multicolumn{3}{c}{$\%$ Change in GSVI Based on State Response } \\
\cline { 2 - 4 } Search Term & All States & Stay at Home & Limited Action \\
\hline ACL & $-28.16 \%$ & $-30.23 \%$ & $-17.26 \%$ \\
Meniscus & $-32.85 \%$ & $-35.01 \%$ & $-21.47 \%$ \\
Rotator cuff & $-28.16 \%$ & $-27.28 \%$ & $-32.71 \%$
\end{tabular}

ACL, anterior cruciate ligament; GSVI, Google Search Volume Index; SD, standard deviation.
COVID-19 pandemic. ${ }^{13}$ Similar to the results of our analysis, the authors found a drop in public interest surrounding hip- and knee-replacement surgery. ${ }^{13}$ It is notable that our analysis covers a slightly different demographic. Although hip and knee arthroplasty is a result of cartilage degeneration over many years, ACL and meniscus injuries, in particular, are often the result of sports or other high-impact activities and, therefore, could be seen in a younger demographic. Many organized sports programs have been canceled as a result of COVID-19 restrictions, and the decrease in public interest surrounding ACL, meniscus and rotator cuff injuries could be a result of a decreased incidence of these injuries. A level 1 trauma center found that between March and April 2020, during the height of the stay-at-home orders, orthopaedic trauma injuries

Table 6. Percentage Decrease in Google Search Volume Index (GSVI) Values Between January 1, 2020-March 15, 2020, versus March 15, 2020-May 10, 2020, for the Terms ACL Surgery, Meniscus Surgery and Rotator Cuff Surgery for all States and Based on State Response

\begin{tabular}{lccc}
\hline & \multicolumn{3}{c}{$\%$ Change in GSVI Based on State Response } \\
\cline { 2 - 4 } \multicolumn{1}{c}{ Search Term } & All States & Stay at Home & Limited Action \\
\hline "ACL surgery" & $-32.05 \%$ & $-29.46 \%$ & $-49.70 \%$ \\
"Meniscus surgery" & $-34.97 \%$ & $-36.74 \%$ & $-22.88 \%$ \\
"Rotator cuff surgery" & $-48.42 \%$ & $-49.75 \%$ & $-39.35 \%$
\end{tabular}

ACL, anterior cruciate ligament; GSVI, Google Search Volume Index; SD, standard deviation. 
(automobile, pedestrian accidents) decreased. ${ }^{19}$ Despite the varying demographic populations for various orthopaedic procedures, it is reasonable to assume that the effects of COVID-19, in sum, have led to an overall decrease in public interest in all elective orthopaedic procedures.

We acknowledge several limitations in the present study. Our analysis was based on GSVI information, and internet searches may not capture perfectly the public's interest in ACL, meniscus and rotator cuff topics and, rather, may act as a proxy to measure interest. Every state had a different response to the US Surgeon General's national recommendation to postpone elective procedures, and there were varying guidelines among the 8 states that had limited-action orders. In addition, different time frames could show different results.

\section{Conclusion}

The COVID-19 outbreak correlated with a decline in public interest in sports-medicine and sports-surgery topics, as measured by Google searches.

\section{References}

1. Satiani B, Zigrang TA, Bailey-Wheaton JL. COVID-19 financial resources for physicians. J Vasc Surg 2020;72: $1161-1165$.

2. Haffer H, Schömig F, Rickert $M$, et al. Impact of the COVID-19 pandemic on orthopaedic and trauma surgery in university hospitals in Germany. J Bone Joint Surg 2020;102:1-12.

3. Cucinotta D, Vanelli M. WHO declares COVID-19 a pandemic. Acta Bio-medica 2020;91:157-160.

4. Paraiso MFR, Brown J, Abrão MS, et al. Surgical and clinical reactivation for elective procedures during the COVID-19 era: A global perspective. J Minim Invasive Gynecol 2020;27:1188-1195.

5. Sarac NJ, Sarac BA, Schoenbrunner AR, et al. A review of state guidelines for elective orthopaedic procedures during the COVID-19 outbreak. J Bone Joint Surg Am 2020;102:942-945.

6. Husain I, Briggs B, Lefebvre C, et al. Fluctuation of public interest in COVID-19 in the United States: Retrospective analysis of Google trends search data. JMIR Public Health Surveill 2020;6:e19969.

7. Panuganti BA, Jafari A, MacDonald B, DeConde AS. Predicting COVID-19 incidence using anosmia and other
COVID-19 symptomatology: Preliminary analysis using Google and Twitter. Otolaryngology 2020;163:491-497.

8. Wu G-C, Tao S-S, Zhao C-N, et al. Leveraging Google Trends to investigate the global public interest in rheumatoid arthritis. Rheumatol Int 2019;39:1439-1444.

9. Dreher PC, Tong C, Ghiraldi E, Friedlander JI. Use of Google Trends to track online behavior and interest in kidney stone surgery. Urology 2018;121:74-78.

10. Strotman PK, Novicoff WM, Nelson SJ, Browne JA. Increasing public interest in stem cell injections for osteoarthritis of the hip and knee: A Google Trends analysis. J Arthroplast 2019;34:1053-1057.

11. Tijerina JD, Morrison SD, Nolan IT, et al. Google Trends as a tool for evaluating public interest in facial cosmetic procedures. Aesthet Surg J 2019;39:908-918.

12. Hanna A, Hanna L-A. What, where and when? Using Google Trends and Google to investigate patient needs and inform pharmacy practice. Int J Pharm Pract 2019;27: 80-87.

13. Jella TK, Samuel LT, Acuña AJ, Emara AK, Kamath AF. Rapid decline in online search queries for hip and knee arthroplasties concurrent with the COVID-19 pandemic. $J$ Arthroplasty 2020;35:2813-2819.

14. Mervosh S, Lee JC, Gamio L, Popovich N. See which states are reopening and which are still shut down. The New York Times. https://www.nytimes.com/interactive/ 2020/us/states reopen-map-coronavirus html. Updated May 2020;8. Accessed June 7, 2020.

15. Centers for Medicare and Medicaid Services releases recommendations on adult elective surgeries, non-essential medical, surgical, and dental procedures during COVID19 response. https://www.cms.gov/newsroom/pressreleases/cms-releases-recommendations-adult-electivesurgeries-non-essential-medical-surgical-and-dental. Accessed August 21, 2020.

16. State Guidance on Elective Surgeries. https://WwW. ascassociation.org/covid-19-state. Accessed August 21, 2020.

17. Moverman MA, Puzzitiello RN, Pagani NR, Barnes CL, Jawa A, Menendez ME. Public perceptions of resuming elective surgery during the COVID-19 pandemic. [published online July 20, 2020]. J Arthroplasty. doi:10.1016/j. arth.2020.07.037.

18. Kolmes S. Employment-based, for-profit health care in a pandemic. Hastings Cent Rep 2020;50:22.

19. Lubbe RJ, Miller J, Roehr CA, et al. Effect of statewide social distancing and stay-at-home directives on orthopaedic trauma at a southwestern level l trauma center during the COVID-19 pandemic. J Orthop Trauma 2020;34:e343-e348. 